\title{
Contrasting contributions of surface hydrological pathways in convection permitting and parameterised climate simulations over Africa and their feedbacks on the atmosphere
}

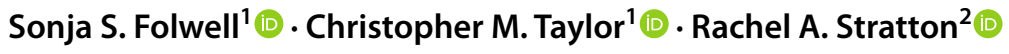

Received: 8 July 2021 / Accepted: 7 January 2022 / Published online: 21 February 2022

(c) The Author(s) 2022

\begin{abstract}
The partitioning of rainfall at the land surface into interception, infiltration and surface runoff plays an important role in the water cycle as it controls the time scale at which water returns to the atmosphere. Rainfall intensity is of crucial importance to this partition. High resolution convection permitting models significantly improve simulated sub-daily rainfall intensity distributions, in particular those associated with convective rainfall in the tropics. Here we compare the land surface hydrological response in a pair of 10-year simulations over an African domain performed using the Met Office Unified Model: a typical configuration using parameterised convection operating at $25 \mathrm{~km}$ and the second a high resolution convection permitting simulation at $4.5 \mathrm{~km}$ with the parametrized convection switched off. Overall pan-African interception in the convection permitting scheme is $70 \%$ lower, whilst surface runoff is $43 \%$ higher than the parameterized convection model. These changes are driven by less frequent, but more intense rainfall with a $25 \%$ increase in rainfall above $20 \mathrm{~mm} \mathrm{~h}^{-1}$ in the $4.5 \mathrm{~km}$ model. The parameterised scheme has a 50\% canopy water contribution to evaporative fraction which is negligible in the convection permitting scheme. Conversely, the convection permitting scheme has higher throughfall and infiltration leading to higher soil moisture in the weeks following rain resulting in a 30-50\% decrease in the daytime sensible heat flux. We examine how important the sub-grid rainfall parameterisation in the model is for the differences between the two configurations. We show how, switching a convective parameterisation off can substantially impact land surface behaviour.
\end{abstract}

Keywords Convection permitting models $\cdot$ Interception $\cdot$ Land atmosphere feedbacks $\cdot$ Rainfall intensity

\section{Introduction}

When rainfall reaches the land surface, it follows different hydrological pathways interception by vegetation, infiltration and percolation through the soil column and runoff. Each pathway has distinct characteristics within the overall water cycle. The vegetated surface accounts for a relatively small reservoir of surface water storage, filling and emptying within hours, yet evaporation of this intercepted water can reach up to $\sim 15 \%$ of annual rainfall in tropical rainforests (Miralles et al. 2011). The water that reaches the ground, either directly, or falling from the vegetation canopy

Sonja S. Folwell

ssf@ceh.ac.uk

1 UK Centre for Ecology and Hydrology, Crowmarsh Gifford, Wallingford, UK

2 UK Meteorological Office, Exeter, UK store, can then infiltrate into the larger soil store. This soil water store is depleted relatively slowly, via transpiration, direct evaporation from the soil surface, and drainage. The third pathway is surface runoff, which occurs when rainfall is intense (infiltration excess runoff), or the soil is already saturated (saturation excess runoff). The physical properties of the surface e.g. vegetation cover and surface infiltrability are important for determining the partitioning between these pathways, as is the rainfall intensity. Light rainfall may be sufficient to wet a vegetated surface but insufficient to contribute to infiltration and surface runoff, whilst higher rainfall rates will quickly exceed canopy capacities and activate the soil surface, with water being partitioned into infiltration (increased soil moisture) and runoff. How the rainfall is partitioned is critical for plant productivity, agriculture and water resources. Equally, the different evaporative time scales associated with these pathways provides an important feedback on the atmosphere which climate models need to capture (Lawrence et al. 2007; Scott et al. 1995). The 
representation of this partitioning at the land surface is challenging for global circulation models (GCMs) (Lian et al. 2018) as the key processes are sub-grid, and can occur in a matter of minutes. This is further compounded by the fact that the rainfall produced by GCMs have significant biases in the frequency and intensity of simulated rainfall (Fiedler et al. 2020; Stephens et al. 2010). These models operate on spatial scales of the order of $100 \mathrm{~km}$ whilst the very intense rainfall-producing storms are an order of magnitude smaller, requiring parameterisations that relate temperature and humidity profiles to convective rainfall. As a result GCMs tend to have incorrect statistics of daily and sub-daily precipitation, producing too many low intensity rain events. Within the framework of parameterised convection schemes, several land surface models include statistically-based parameterisations that attempt to account for the sub-grid variability of the incoming rainfall within a single GCM grid box (Best et al. 2011; Wang et al. 2009; Decharme and Douville 2007; Schmidt et al. 2006). Furthermore steps to improve the runoff generating characterises include additional parameterisation of surface heterogeneity which also impact soil moisture (Beven and Kirkby 1979; Moore 1985; Wood et al. 1992).

Experiments with GCMs have shown sensitivity of canopy evaporation to near surface air temperature and humidity and in turn the development of clouds (Lawrence et al. 2007; Wang et al. 2009; Davies-Barnard et al. 2014). A recent study of evaporation partitioning into plant transpiration and bare soil and canopy evaporation in CMIP5 models (Lian et al. 2018) found interception losses contributed to incorrect partitioning of total evaporation, with rainfall frequency a likely contributor to this overestimate.

Since problems with the partitioning of water in climate models is attributed to biases in rainfall intensity as well as the treatment of rainfall by the land surface scheme, recent advances to improve rainfall characteristics have impacted the hydrological partitioning. Super-parameterizations in GCMs (Demott et al. 2007) improve the depiction of rainfall intensity and frequency, and subsequent canopy interception, which also led to improved coupling strength between the land and atmosphere over tropical forests (Sun and Pritchard 2016). Renewed interest in the hydrological partitioning of rainfall from the climate modelling community has also been triggered by the increasingly widespread use of models with much lower horizontal grid spacings $(<5 \mathrm{~km})$, allowing the deep convective parameterisation to be switched off (Prein et al. 2015) and more recently in ensemble simulations (Ban et al. 2021; Pichelli et al. 2021). These convection-permitting models (CPMs) simulate the vertical updrafts and down draughts within single storms, and can resolve the broader scale organization of convection into mesoscale convective systems (Clark et al. 2016). They tend to improve the diurnal timing of rainfall (Clark et al. 2016), the longevity of storms (Crook et al. 2019), the distribution of sub-daily rainfall intensities (Senior et al. 2021), and the depiction of land-atmosphere feedbacks (Taylor et al. 2013; Hohenegger et al. 2009). Such models have been routinely used for short-term operational forecasts for over a decade e.g. the UK Met Office (MetUM) configuration (Lean et al. 2008), but advances in computing power and more efficient codes allow multi-year regional simulations, and even month-long global simulations (Stevens et al. 2019).

The ability to run CPM simulations longer than a few days means that any changes in partitioning of rainfall into its different pathways due to improved spatial and temporal model resolution can have potentially important consequences for the atmosphere via feedbacks in evaporative response. For example, Hu et al. (2020) have shown how the intense rain produced by organised convective systems in the United States can percolate deeper, and affect the time scale of feedback with subsequent storms. Several authors have noted a tendency towards drier soil moisture stores when comparing CPM runs with parameterised models. For example (Ban et al. 2014) speculated on the role of more frequent light rain simulated by their convective parameterisation for enhancing soil moisture deficit in a 10-year European simulation. In a seasonal CPM simulation over China, ( $\mathrm{Li}$ et al. 2020) also found increased sensible heat flux at the expense of latent heat which they argued was contributing to biases in the diurnal cycle of rainfall. Over India, Willetts et al. (2017) attributed increased sensible heat in a CPM simulation to increased insolation coupled with soil moisture deficit from reduced interception loss and increased runoff. They found that this enhanced the land-sea pressure difference (compared to a parameterised simulation) and increased onshore flow.

In this study we provide a detailed examination of how switching from parameterised convection to convectionpermitting in a regional climate model affects the partition of rainfall into different hydrological pathways, and how this partitioning feeds back into the simulation of the atmosphere. We focus on a pair of 10-year simulations over a pan-African domain using the UK Met Office model (Stratton et al. 2018). This model is increasingly being used in long convection-permitting simulations, and previous studies with it have noted important changes in surface hydrological behaviour when switching to convection-permitting mode e.g. Li et al. (2020), Kendon et al. (2012) and Willetts et al. (2017). By looking in detail at the surface hydrology parameterisation in this model, our analysis sheds new light on those studies. However, our focus on changes in surface hydrological fluxes and stores is also relevant for long integrations using other CPMs which have reported enhanced dry soil biases e.g. (Ban et al. 2014) compared to coarser resolution simulations.

In Sect. 2 we describe the model and experimental design, with a particular focus on the surface hydrology. 
This is followed by analysis of the continental scale differences in rainfall and its partitioning in Sect. 3.1, the impact of these differences on the diurnal cycle via interception feedbacks (3.2), and the feedback on the atmosphere via soil moisture on seasonal time scales (3.3). The results are discussed in Sect. 4.

(a) CHIRPS vn2.

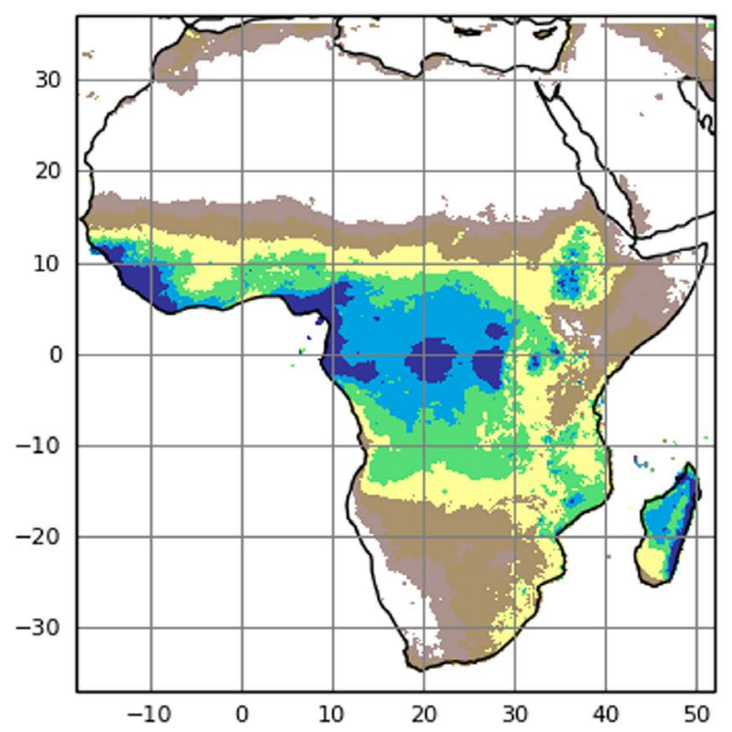

(c) R25

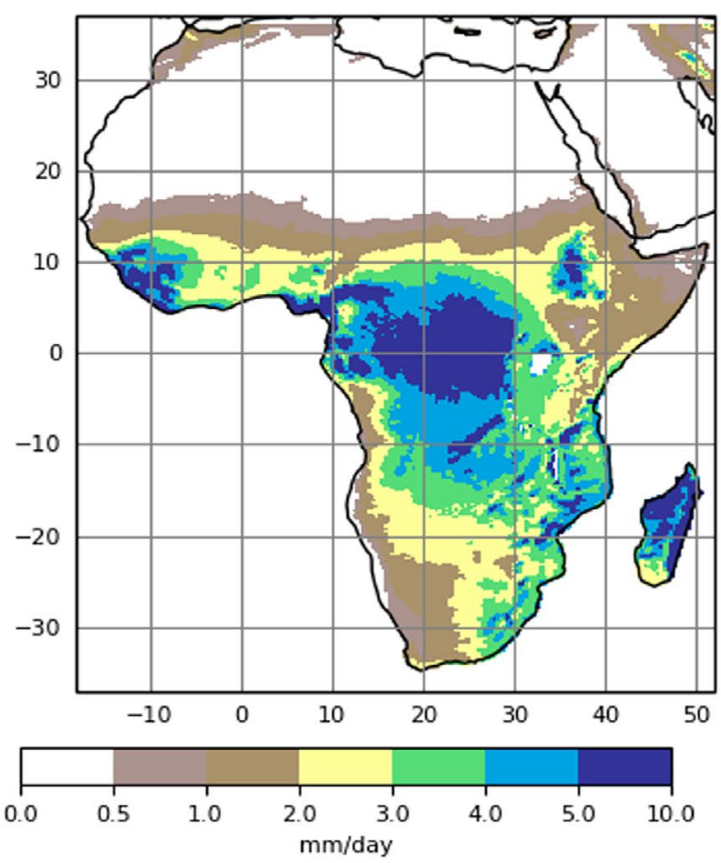

\section{Data and models}

This study takes advantage of a pair of 10-year pan-African simulations using the UK Met Office Unified Model designed to understand how the representation of convection affects African climate and climate change (Senior et al. 2021). One simulation (R25) is run with a conventional convective parameterization on a horizontal grid of $\sim 26 \times 39 \mathrm{~km}$

(b) CP4

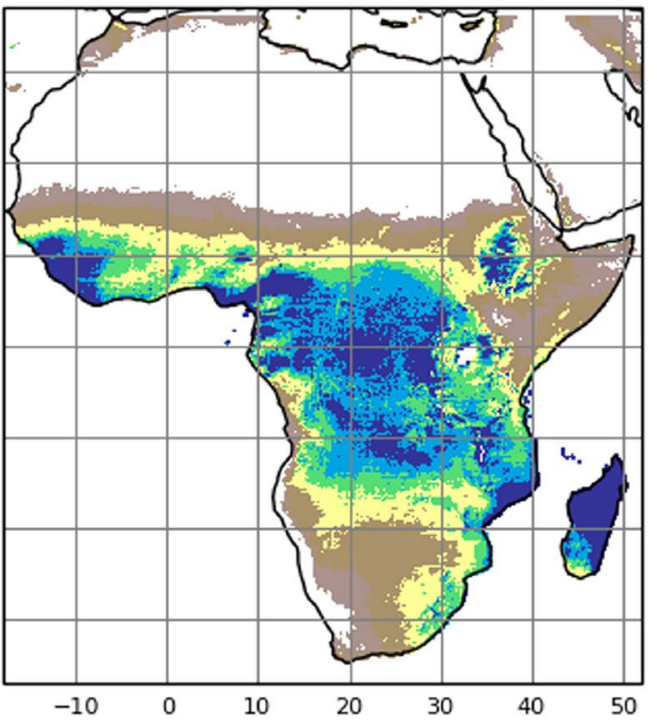

(d) CP4 - R25

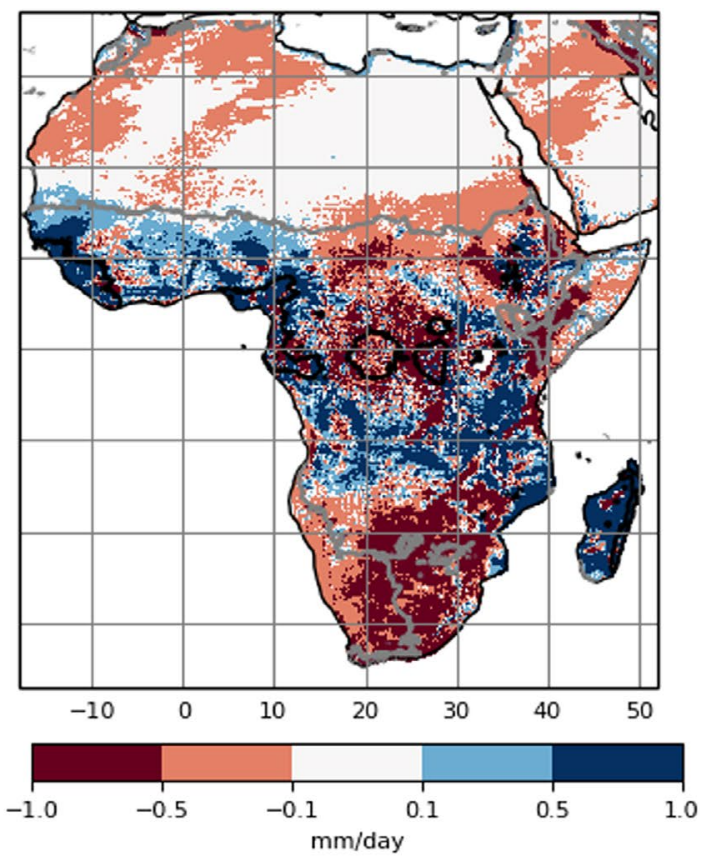

Fig. 1 Comparison of annual rainfall (mm/day) over land for a CHIRPS v2, b CP4, $\mathbf{c}$ R25 and d the model difference over plotted with CHIRPS contour levels $1 \mathrm{~mm} \mathrm{day}^{-1}$ (grey); $5 \mathrm{~mm} \mathrm{day}^{-1}$ (black) 
over a domain from $39 \mathrm{~N}$ to $45 \mathrm{~S}, 25 \mathrm{~W}$ to $56 \mathrm{E}$ (Fig. 1). A second convection-permitting simulation (CP4), is run on the same domain, with the same boundary conditions, but with a regular horizontal grid of $4.5 \times 4.5 \mathrm{~km}$ at the equator, and parameterized convection switched off. The cloud schemes used in the two models are different. CP4 has 80 model levels and uses the diagnostic cloud scheme (Smith 1990) whereas R25 has 63 model levels and uses the prognostic PC2 cloud scheme (Wilson et al. 2008). Rainfall in CP4 is determined only by the large-scale precipitation scheme. Both models are driven by 3-hourly lateral boundary conditions from a global $25 \mathrm{~km}$ simulation, N512L85 protype version of the Global Atmosphere 7 (GA7) and Global Land 7 (GL7) (Walters et al. 2019), which is forced with present day sea surface and lake temperatures for the years 1997 to 2006, see Stratton et al. (2018) for more details. The CP4 simulations are computationally demanding, but have provided a unique continental-scale depiction of climate change over tropical land with a convection-permitting model. Many analyses have already been published on these simulations (Senior et al. 2021), which have demonstrated advances in the representation and understanding of tropical land-based convection and how this might change over the 21 st Century. Comparisons with observations have shown that $\mathrm{CP} 4$ exhibits more realistic rainfall properties than $\mathrm{R} 25$, including improvements in the diurnal cycle (Stratton et al. 2018), intensity distribution (Senior et al. 2021; Berthou et al. 2019) and storm size and duration (Crook et al. 2019). None of the studies to date have focused on how the representation of land-atmosphere interactions is affected by the representation of convection, which is the topic of this work. We analyse only the two simulations under current climate conditions, and leave analysis of how land-atmosphere coupling within a convection-permitting framework may influence climate change projections to future work.

Whilst more general details of the model set up are described elsewhere (Stratton et al. 2018), below we outline aspects of the land surface model which are key to understanding differences in land-atmosphere coupling between the two simulations. The Joint UK Land Environment Simulator (JULES) land surface model (Best et al. 2011) provides the lower boundary of energy and mass fluxes to the atmosphere. Fluxes are computed on 9 land tiles according to 5 plant functional types (broadleaved tree, needle leaved tree, shrub C4 and C3 grasses) and 4 non-plant functional types (urban, water, bare soil and ice), which share a single four level soil moisture store. The configuration of JULES is based on the "GL7" configuration (Wiltshire et al. 2020) and is used in both CP4 and R25.

The vegetation fractions used here were derived from European Space Agency-Climate Change Initiative land cover datasets (Poulter et al. 2015), providing mapping from biome to model plant functional type, and give a more realistic distribution of bare soil. A climatology of leaf area index derived from MODIS collection 5 dataset provide seasonal vegetation changes. Previous convectionpermitting studies over West Africa found the mapping of soil properties introduce artificial boundaries that can unduly influence the sensitive soil moisture - precipitation feedbacks (Taylor et al. 2013). Therefore in these simulations spatially uniform properties of sand were adopted. Soil moisture initialisations consistent with these uniform soil properties were generated from offline simulations driven by WATCH Era Interim Forcing data (Weedon et al. 2011). The 0.5 degree soil moisture climatology was computed from 10 years of simulation and downscaled to the CP4 and R25 model resolutions.

The JULES model simulates a canopy water balance above four soil layers on which soil moisture and temperature are computed. The canopy water balance is solved for each tile, with each tile having its own maximum canopy capacity (up to $1.05 \mathrm{~mm}$ for broadleaf trees), and which depends on leaf area index. The canopy store is replenished by rainfall and depleted by evaporation. Canopy evaporation is rapid as there is no evaporative resistance. Rainfall in excess of the canopy capacity reaches the soil surface as throughfall. Through fall is partitioned between the top level soil moisture and surface runoff. The latter includes both infiltration-excess runoff (when throughfall rates exceed the infiltration capacity) and saturation excess runoff. In this configuration saturation excess runoff (that is surface runoff produced when rain falls onto saturated ground) is modelled by the probability distributed moisture scheme (Moore, 1985), and related to the soil moisture in the top $1 \mathrm{~m}$ (3 levels). The infiltration capacity is based on the product of the saturated soil hydraulic conductivity and a vegetation enhancement factor, which takes values of 2 for grass and 4 for trees. Each grid box has soil moisture reservoir which is shared cross all the tiles, and divided into four soil layers of depths $0.1,0.25,0.65$ and $2.0 \mathrm{~m}$ depth. Flow between the soil layers is computed following Richards equation for unsaturated flow, with water draining from the lowest level being sub-surface runoff. The relationship between soil matric potential and soil moisture and unsaturated hydraulic conductivity is defined by van Genuchten (1980). Transpiration is extracted from the soil profile based on an exponential root distribution. Bare soil evaporation occurs only from the top level, and sub-surface runoff is made up of water that drains out from the lowest soil level.

To address the problem of modelling sub-grid variability in surface hydrological fluxes over a GCM grid box described in the Introduction, the Unified Model assumes an exponential sub-grid rainfall distribution when calculating the canopy water balance and surface runoff (Dolman and Gregory 1992). 
$f\left(P_{l}\right)=\left(\frac{\mu}{P}\right) \exp \left(\frac{-\mu P_{l}}{P}\right)$

where $P_{1}$ is the distribution of rainfall intensities for a given grid box mean rainfall, $\mathrm{P}$ and the rainfall area fraction, $\mu$ controls the shape of the distribution of rainfall intensities. For rainfall from the convective parameterisation, $\mu$ varies with rainfall rate, typically taking a value $\sim 0.3$, whilst for rainfall from the large-scale scheme, $\mu=1$. Whilst the land surface parameters specified in the two model configurations are identical, they differ significantly in their assumed subgrid rainfall distribution, because the overwhelming majority of rain in R25 is produced by the convective scheme (so $\mu \sim 0.3)$, whilst CP4 rain is all large-scale $(\mu=1)$.

The exponential distribution is used to derive throughfall,

$\operatorname{Tr}=P\left(1-\frac{C}{C_{m}}\right) \exp \left(\frac{-\mu C_{m}}{P \Delta t}\right)+P \frac{C}{C_{m}}$

where $\mathrm{C}$ is the canopy water, $\mathrm{C}_{\mathrm{m}}$ the maximum canopy capacity, and $\Delta \mathrm{t}$ is the model time step. Infiltration excess runoff is given by (Best et al. 2011; Dolman and Gregory 1992),

$Y= \begin{cases}P \frac{C}{C_{m}} \exp \left(\frac{-\mu K C_{m}}{P C}\right)+P\left(1-\frac{C}{C_{m}}\right) \exp \left(\frac{-\mu C_{m}}{P \Delta t}\right), & K \Delta t \leq C \\ P \exp \left(-\frac{\mu\left(K \Delta t+C_{m}-C\right)}{P \Delta t}\right), & K \Delta t>C\end{cases}$

where $\mathrm{K}$ is the surface infiltration rate, and is computed from the saturated hydraulic conductivity multiplied by an infiltration enhance factor, which in turn is related to the land cover type. Eqs. 2 and 3 are applied to each tile, and grid box mean fluxes and canopy water computed by area-weighting the tiles. The difference between grid box mean values of throughfall and infiltration excess runoff enter the top model soil level.

During the CP4 simulations, the soil moisture was inadvertently reset to saturation when the model was restarted on 1/7/1997 i.e. 6 months into the simulation. A repeat 12-month simulation initialised with the correct soil moisture on 1/7/1997 was performed, and the output of the model patched into the 10-year time series. This approach corrected the large but short-lived impact on surface fluxes (see Appendix A of Stratton et al. 2018). However the patching in of the data did result in some discontinuities in the time series of deep (i.e. below the root zone) soil moisture, and sub-surface runoff in arid and sparsely-vegetated regions (notably the Sahara). This patching process didn't have any noticeable impact on the atmosphere at the monthly time scale, and its impact on the terrestrial water budget is discussed later.

The simulations output hourly-mean land surface fluxes, with accumulated rainfall available hourly in R25 and every 15 min in CP4. In our analysis of the diurnal cycle, these variables have been adjusted to local solar time. The results presented in this paper are computed using 9 years of simulation from $1 / 1 / 1998$ to $30 / 12 / 2006$, and hourly and daily diagnostics.

\section{Results}

\subsection{Large scale water balance and partitioning}

To begin, we compare continent-wide terrestrial water budgets between the two simulations. Mean annual totals for mainland Africa (excluding Madagascar) are presented in Table 1. Averaged across Africa, mean rainfall is $1.86 \mathrm{~mm} \mathrm{day}^{-1}$ for both models, (Table 1), though there are notable rainfall differences within the continent (Fig. 1). Despite comparable rainfall inputs, the two simulations partition the surface water very differently. At the pan-Africa scale (Table 1) total evaporation (that is transpiration, bare soil and canopy evaporation) in R25 is higher and represents a higher proportion of the surface water budget $(75 \%$ of rainfall) compared to $\mathrm{CP} 4$ ( $62 \%$ of rainfall). Crucially, it is the difference in modelled interception $\left(0.23 \mathrm{~mm}\right.$ day $\left.^{-1}\right)$ that accounts for the vast majority of the difference in total evaporation $\left(0.24 \mathrm{~mm} \mathrm{day}^{-1}\right)$ between the two models. Evaporation of water intercepted by the canopy in R25 is a remarkable 3.6 times larger than in CP4. The two simulations also differ substantially in total runoff. Annual runoff

Table 1 Long term water balance components in $\mathrm{mm} \mathrm{day}^{-1}$ (percentage of rainfall) over mainland Africa (excluding Madagascar)

\begin{tabular}{lllllll}
\hline & Rainfall & Canopy evaporation & Total Evaporation & Total runoff & Surface runoff & Sub-surface runoff \\
\hline $\begin{array}{l}\text { Observational estimates } \\
\text { Models 1998-2006 }\end{array}$ & $1.84(\mathrm{a})$ & $0.09(\mathrm{~b})$ & $1.32(\mathrm{~b})-2.26(\mathrm{c})$ & $0.41(\mathrm{~d})$ to $0.53(\mathrm{e})$ & - & - \\
R25 & 1.86 & $0.32(17 \%)$ & $1.40(75 \%)$ & $0.47(25 \%)$ & $0.37(19 \%)$ & $0.09(4 \%)$ \\
CP4 & 1.86 & $0.09(5 \%)$ & $1.16(62 \%)$ & $0.75(40 \%)$ & $0.53(28 \%)$ & $0.23(12 \%)$ \\
CP4-R25 & 0.00 & $-0.23(-12 \%)$ & $-0.24(-13 \%)$ & $0.28(15 \%)$ & $0.16(9 \%)$ & $0.14(8 \%)$ \\
\hline
\end{tabular}

(a) Funk et al. (2015); (b) Martens et al. (2017); (c) Jung et al. (2019); (d) Dai and Trenberth (2002); (e) Rodell et al. (2015) Table 3 (includes Madagascar) 
is higher in CP4 (40\% of rainfall) compared to R25 (25\%). This difference is made up of contributions from both surface runoff and subsurface runoff. We note that because of the issues discussed above concerning the restart of CP4 and its erroneous wet soil re-initialisation, the deep soil moisture was not fully spun-up in drier parts of the domain, even after the remaining 8.5 years of simulation. This results in a small increase $(0.04 \mathrm{~mm} /$ day $)$ in sub-surface runoff in unvegetated arid areas (e.g. the Sahara) where losses are by drainage only, but overall the differences in sub-surface runoff between the simulations are small. On the other hand, we found that the impact of the soil moisture re-initialisation on evaporation was negligible after 12 months. This is because spin-up issues in level 4 soil moisture were only evident in dry regions (notably the Sahara). In these areas there is no deep-rooted vegetation to extract soil moisture, and hence no ability to influence transpiration.

In Table 1 we also include observational estimates of the different terms in the pan-African water balance, where available. Comparing with mean rainfall from the CHIRPS v2 dataset (Funk et al. 2015), the simulations are close to the observed over the same years (1998 to 2006), though at sub-continental scale, rainfall biases in one or both simulations can be larger, as previously presented by Stratton et al. (2018) and Jackson et al. (2020). For the remaining water fluxes, the observational estimates come with large uncertainties and are included here only to provide a "ballpark figure" to compare with the two simulations. Considering total evaporation, R25 sits within the estimated range, whereas $\mathrm{CP} 4$ evaporation lies $12 \%$ below the minimum estimate. The only available global estimate of canopy evaporation (Martens et al. 2017) suggests a $320 \%$ over-prediction by R25, but very similar interception loss to CP4. Finally, we note that pan-African runoff, R25 again is within the estimated range whereas CP4 over-predicts by up to $85 \%$, though the observational datasets include losses due to lakes, reservoirs, abstractions and within river losses which are not represented by these simulations. Comparisons with observational estimates of evaporation and runoff over a region as sparely-observed as Africa are fraught with difficulty. However, we do note that the estimate of continent-wide interception losses as a percentage of rainfall from R25 does also appear to be excessive in comparison with in situ observations from tropical broadleaved evergreen forests; $8.9 \%$ (Lloyd et al. 1988); 11.6\%; (Urabana 1997) 13.3\% (Cuartas et al. 2007); 13.5\% (Tobon Marin et al. 2000); $11.6 \%$ (Czikowsky and Fitzjarrald 2009); 9.1\% (Shuttleworth 1988) in Amazonia and 9.2\% (Hutjes et al. 1990) in West Africa. As interception loss should decrease strongly away from the densely-vegetated forests of Central and Western Africa, we conclude that the continent-wide interception loss of $18 \%$ in R25 is not realistic. In summary, at the continental scale the two models have similar total rainfall but quite distinct partitioning of that rainfall. The $\mathrm{CP} 4$ simulation produces much less evaporation than $\mathrm{R} 25$, and this is primarily due to reduced canopy interception. The reduction in evaporation in CP4 is offset by an increase in both surface and sub-surface runoff. Observation-based estimates of terrestrial water fluxes over Africa are rather uncertain, but the high rates of interception loss in R25 appear unrealistic in comparison to both pan-African and local estimates.

The sub-grid rainfall assumption applied to the model's canopy hydrology and infiltration excess runoff calculations (described in Sect. 2) is expected to reduce changes in the partition of rainfall between hydrological pathways at different model resolutions. It is clear from the above discussion that that goal is not achieved in this pair of simulations. We can understand the differences between simulations by considering the differences in rainfall intensities, as shown for a small region in Central Africa, 27.8 to $28.8^{\circ} \mathrm{E}, 4.5$ to $5.5^{\circ} \mathrm{N}$ (Fig. 2a, and repeated in Fig. 2b). This region is selected for having similar mean hourly rainfall in both simulations. Here the hourly rainfall for 9 years in the two simulations have been binned following the logarithm-based formula presented by Klingaman et al. (2017), and shows the contribution of each bin to the hourly mean rainfall. It should be noted that for this analysis of grid box scale processes, we are sampling the models on their native grids. As highlighted in previous analyses of these simulations using a common $25 \mathrm{~km}$ grid (Senior et al. 2021), (Stratton et al. 2018) CP4 produces a larger fraction of its total rainfall in the higher intensity bins than R25, bringing CP4 much more into line with observations (Senior et al. 2021). The impacts on canopy interception and infiltrationexcess runoff of simply switching from a rainy area fraction of $\mu=0.3$ (a typical value for R25) to $\mu=1$ (as prescribed in CP4) are illustrated in Fig. 2c and d. These plots show the functional relationships between the grid box mean rainfall, and interception (rainfall minus throughfall) and infiltration excess runoff, as described in Eqs. 2 and 3. Here we have assumed values of canopy capacity and vegetation infiltration enhancement factor of $0.55 \mathrm{~mm}$ and 2 (as used for the grass tiles), a dry canopy, and saturated hydraulic conductivity of $0.019 \mathrm{~mm} \mathrm{~s}^{-1}$ (as prescribed uniformly in both models). For each bin and each simulations we have then multiplied the simulated rainfall spectra (Figs. 2a, b) by their respective sub-grid rainfall distributions (Figs. 2c, d) to compute the combined impact of differences in rainfall distribution and differences in $\mu$ on interception (Fig. 2e) and infiltration-excess runoff (Fig. 2f). Comparing the sum of the bins we estimate the interception to be $0.026 \mathrm{~mm} / \mathrm{h}$ and $0.017 \mathrm{~mm} / \mathrm{h}$ for R25 and CP4 respectively for this region. Figure 2e illustrates clearly why both interception and percentage interception loss (interception/rainfall) is higher in R25 (15\%) than CP4 (9\%). In R25, the high frequency of light rainfall (less than $1 \mathrm{~mm} \mathrm{hr}^{-1}$ ) contributes to the larger interception losses, in spite of the assumption of rainfall only occurring over $30 \%$ of the grid box. At the larger rainfall 

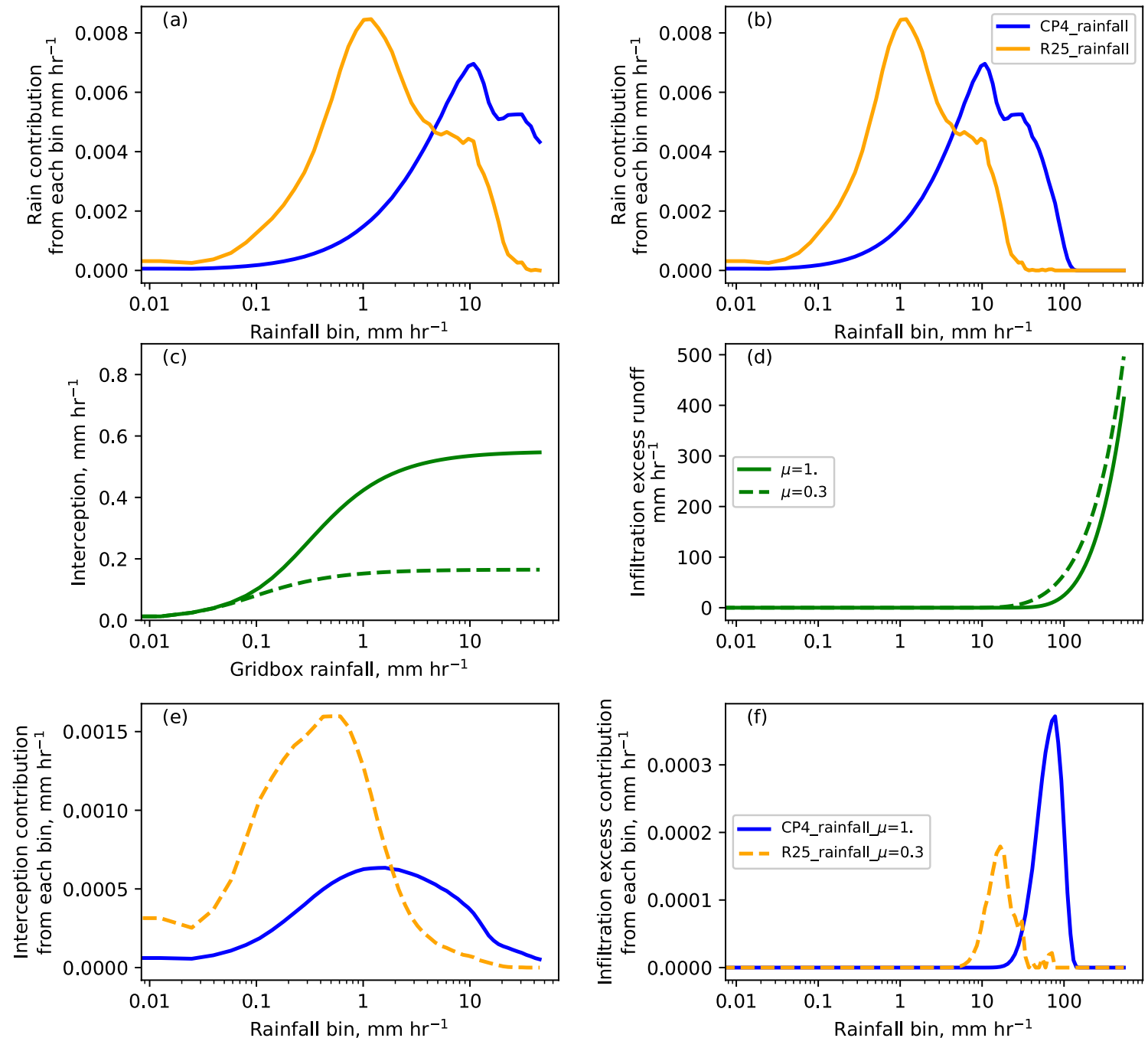

Fig. 2 a and $\mathbf{b}$ show the contribution of hourly rainfall in CP4 (blue) and R25 (orange) to average grid box rainfall over a Central Africa sub-region $\left(27.8-28.8^{\circ} \mathrm{E}, 4.5-5.5^{\circ} \mathrm{N}\right)$. The same distributions are shown on $\mathbf{a}$ and $\mathbf{b}$ but the $\mathrm{x}$-axis range is reduced for ( $\mathrm{a}, \mathrm{c}$ and $\mathrm{e}$ ). The sub-grid rainfall relationships from Eqs. 2 and 3 for $\mathbf{c}$ interception and d infiltration excess runoff respectively, under different assumptions

of rainfall area fraction corresponding those of to CP4 $(\mu=1)$ and R25 $(\mu=0.3)$. The contribution of each rainfall bin to $\mathbf{e}$ interception and $\mathbf{f}$ infiltration excess runoff, constructed by weighting the interception and infiltration excess runoff curves by the corresponding model rainfall spectra

rates typical of $\mathrm{CP} 4$, the vast majority of rainfall falls through the canopy to the ground. At the pan-African scale, this leads to canopy interception in R25 almost 4 times as large as in CP4 (Table 1). The impact of contrasting rainfall intensities on infiltration excess runoff between the two simulations accounts for a smaller proportion of the water budget than interception. As expected, higher rainfall rates in $\mathrm{CP} 4$ yield a higher infiltration excess runoff i.e. $0.004 \mathrm{~mm} / \mathrm{h}$ compared to $0.001 \mathrm{~mm} / \mathrm{h}$ in R25. However, the combined impact of interception and infiltration excess runoff means that, $\mathrm{CP} 4$ delivers a similar proportion (89\%) of its rainfall as infiltration as R25 (85\%). In this particular example, infiltration excess runoff is larger in $\mathrm{CP} 4$ than R25, but note that this ignores the role of the large

scale hydrology scheme that also contributes to the surface runoff reported in Table 1.

Finally we note that CP4 has lower insolation than R25 due to differences in the cloud scheme, and higher, brighter clouds in CP4. This difference is particularly true in the presence of convective rainfall (Stratton et al. 2018). However in the next section we do not see a strong impact of this on the role of canopy evaporation in the hours after rain.

\subsection{Feedbacks on the diurnal cycle via canopy interception}

We next consider how the differences in canopy interception between the two simulations affect the atmosphere over the 
diurnal cycle. This feedback is rapid as the canopy store is small (typically $0.5 \mathrm{~mm}$ ), and when full, evaporates at potential rates $\sim 3-5 \mathrm{~mm} \mathrm{day}^{-1}$, dominating the energy partition in the hours after rain. Moreover, the diurnal cycles of rainfall differ between CP4 and R25 (Fig. 3). As shown in other studies e.g. Dai (2006) and Guichard et al. (2004) the parameterised convective schemes tend to trigger convection too easily, leading to a model that starts raining earlier in the day. This is true for R25 in which rainfall peaks at $1300 \mathrm{~h}$ compared with $1600 \mathrm{~h}$ in $\mathrm{CP} 4$.

The evaporative fraction (EF) is a simple measure of the surface flux partitioning of available energy (total energy at the surface) into latent and sensible heat, defined as the latent flux divided by the sum of sensible and latent fluxes. In Fig. 4 we show how the contrasting diurnal cycles of rainfall between the two simulations, in combination with their distinct canopy interception behaviours, affects the diurnal cycle of EF. Maps of the afternoon minus the morning EF differences for R25 and CP4 for March to May are shown Figs. $4 \mathrm{a}$ and $\mathrm{b}$ respectively, though similar features are found in other seasons. In R25, afternoon EF is typically $0.05-0.1$ higher than in the morning right across subSaharan Africa, with a particularly strong signal over West Africa. By contrast, CP4 has only a weak morning to afternoon increase in EF. The difference between these two fields (Fig. 4c) demonstrates across tropical North Africa a much greater increase in latent heat flux during the afternoon in R25 at the expense of the sensible heat flux.

We now use the southern West Africa region $\left(-8\right.$ to $6^{\circ} \mathrm{E}$, 5 to $10^{\circ} \mathrm{N}$, land points only, indicated in Fig. 6) to look at the different model responses over the diurnal cycle, again averaged over the March-May season (Fig. 5). Here EF is computed for daytime hours when total available energy is greater than $100 \mathrm{Wm}^{-2}$. The EF is computed on the native model grid

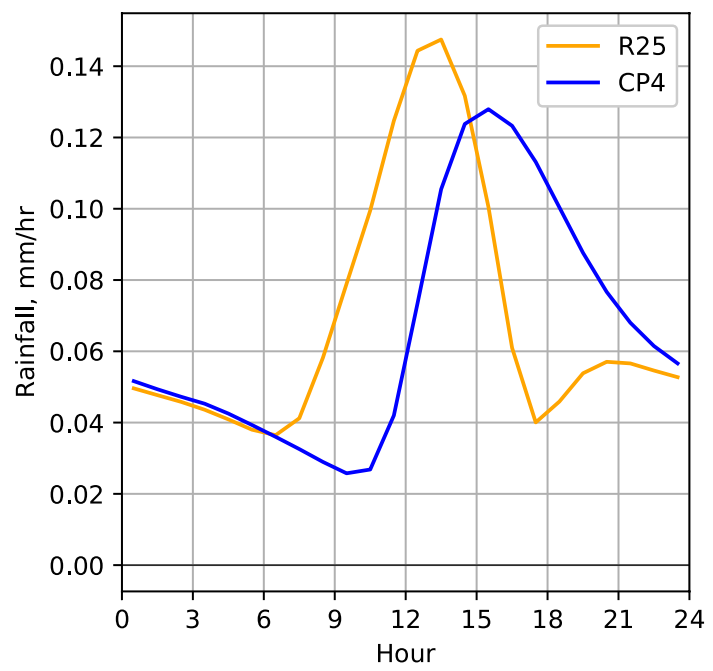

Fig. 3 Pan-African diurnal cycle of rainfall over land for MAM and regridded to the $25 \mathrm{~km}$ model grid for comparison. Considering the parameterised model first, the rainfall (Fig. 5a) is near zero at 0600 LT but increases through the morning, peaking at 1300 LT. Meanwhile the partitioning of energy (Fig. 5b) switches from being equally apportioned to sensible and latent heat (EF of 0.5 at $1200 \mathrm{LT}$ ) to one dominated by latent heat (EF $\sim 0.67$ at $1500 \mathrm{LT}$ ). The dashed line indicates the canopy evaporation component of evaporative fraction, computed as the ratio of canopy latent heat flux to the available energy. Canopy EF rises from 0.11 at $1000 \mathrm{LT}$ to 0.27 at $1500 \mathrm{LT}$ in $\mathrm{R} 25$, and is clearly responsible for the overall daytime rise in EF seen in Fig. 5b. In CP4 on the other hand, EF is relatively constant during the day, but rises in late afternoon in response to the peak in rainfall and associated canopy evaporation. In Fig. $5 \mathrm{c}$ we see that up to mid-morning, with similar levels of available energy to CP4, R25 produces slightly stronger sensible heat (when the canopy is fairly dry), and has a more rapid decline in the afternoon. That rapid afternoon decline is due to a combination of a wetter canopy (which increases EF) and reduced available energy. The feedback in R25, whereby excessive canopy evaporation and changes in surface insolation suppress afternoon heating and thereby reduces convergence of moisture at low levels, contributes to the reduced amplitude of the diurnal cycle of column moisture flux convergence in R25 (Fig. 5d). Effectively, canopy evaporation in R25 is bringing forward the phase of diurnal heating by $1-2 \mathrm{~h}$, enhanced by additional cloud shading.

We now consider how the rapid afternoon decrease in sensible heat in R25 impacts the atmosphere. In this coastal region, we see differences in the sea breeze circulation between the two simulations (Fig. 6). Suppressed afternoon surface heating in the rainiest coastal areas in R25 reduces the land-sea pressure difference, in turn weakening the sea breeze. Though weaker than at the coast, this pattern of reduced afternoon convergent flow in R25 is evident across the interior of the region. The feedback in R25, whereby excessive canopy evaporation suppresses afternoon heating and thereby reduces convergence of moisture at low levels, contributes to the reduced amplitude of the diurnal cycle of column moisture flux convergence in R25 (Fig. 5d). Better resolution in $\mathrm{CP} 4$ of purely atmospheric processes presumably also plays a role in the moisture flux convergence differences between the two simulations (Finney et al. 2019). Overall, the more sustained moisture convergence evident during late afternoon in CP4 will help to maintain rainfall well into the evening in that model (Fig. 5a,d), in better agreement with observations.

\subsection{Feedbacks on the seasonal time scale via soil moisture}

Having identified a strong impact of water budget partitioning on the atmosphere at the diurnal time scale, we 


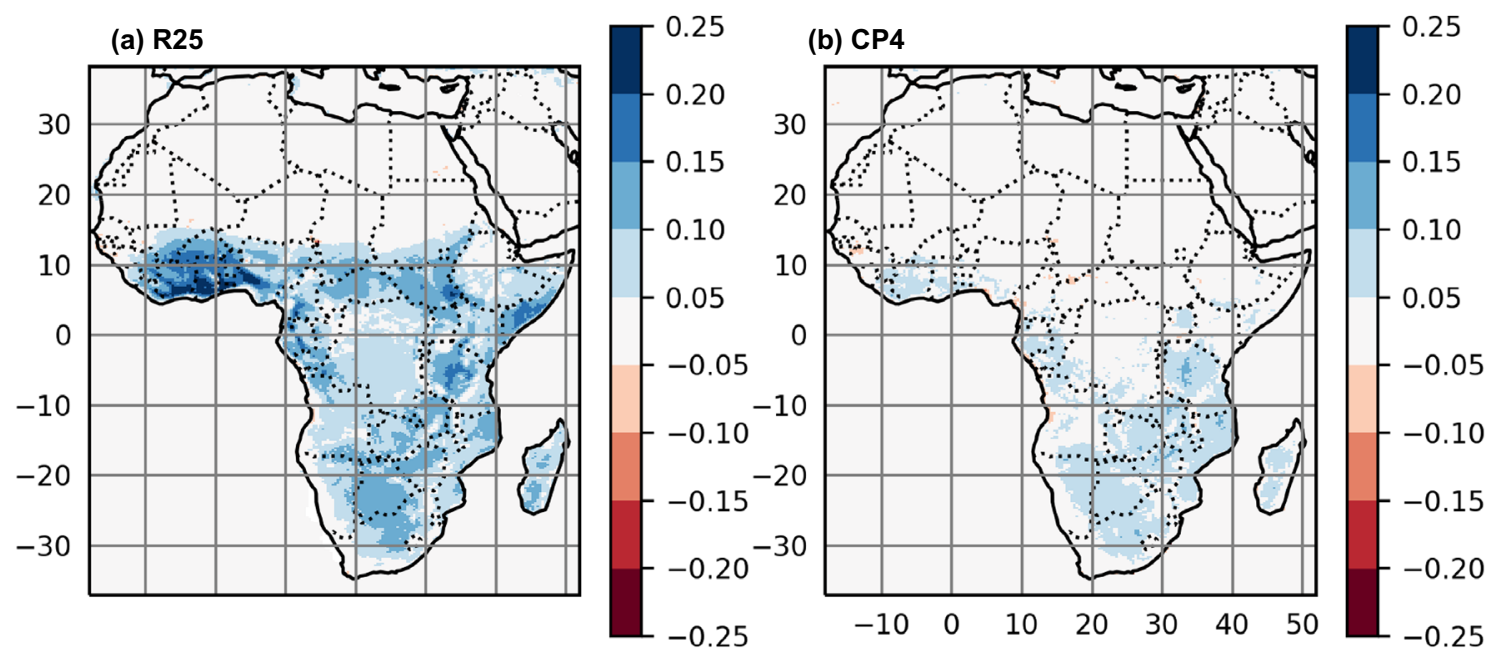

(c) CP4 - R25

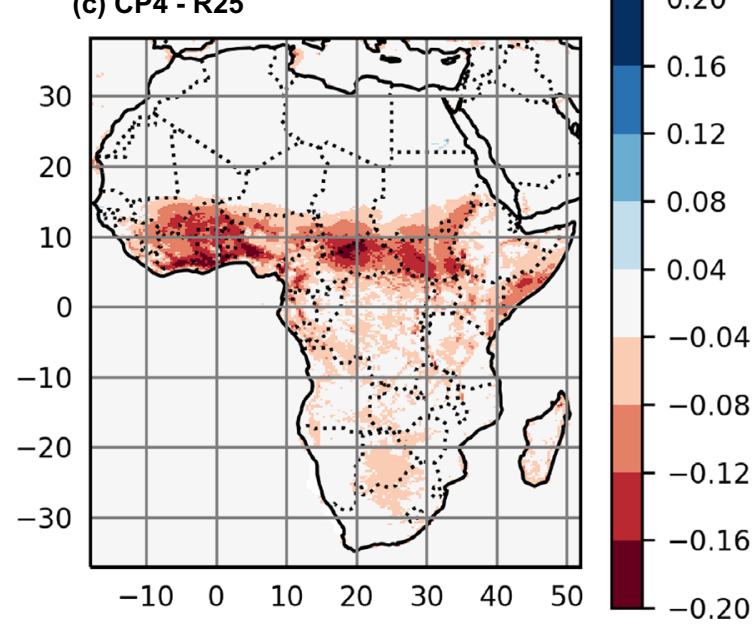

Fig. 4 Afternoon (1300-1500 LT) minus morning (0900-1100 LT) evaporative fraction (EF) for MAM for a R25 b CP4 and c model difference CP4-R25

now examine its impact at the seasonal time scale, via soil moisture. Soil moisture state integrates the effect of rainfall partitioning and evaporation over a range of timescales. In Fig. 7 we present the annual cycle of the key components of the water balance (rainfall $(\mathrm{P})$, throughfall, evaporation (E), runoff, soil moisture and $\mathrm{P}-\mathrm{E}$ ) as a function of latitude. Both models show the seasonal migration of the rain band which characterises African climate. However south of $20^{\circ}$ S CP4 has lower rainfall in all months (Fig. 7c), related to the improved representation of convection in tropical -extratropical cloud bands (Hart et al. 2018). In Equatorial and Northern Africa, CP4 has lower rainfall during months January to April but higher rainfall later in the year.

The large differences in interception loss between models means that the pattern in throughfall (Fig. 7d-f) is modulated compared to the rainfall forcing. The surface beneath the canopy receives a larger fraction of rain in $\mathrm{CP} 4$ than R25, shifting the features in Fig. 7c towards more positive values in Fig. 7f. This shift towards enhanced water fluxes in $\mathrm{CP} 4$ is reinforced when considering surface runoff. Even in latitude-months where $\mathrm{CP} 4$ delivers much less rain than R25 (e.g. Equatorial Africa during boreal winter), this difference is not translated into less surface runoff. Compared to R25, enhanced surface runoff in CP4 is due to a combination of reduced interception loss and more efficient runoff generation because of higher rainfall intensities. Similarly, sub-surface runoff is greater in CP4 for all latitude-months. This reflects increased infiltration (throughfall minus surface runoff) and hence soil moisture in CP4. The sub-surface runoff differences (Fig. 71) lag the surface runoff pattern (Fig. 7i) by 1 to 2 months due to the time taken for rainfall to travel down through the profile to the bottom soil layer 

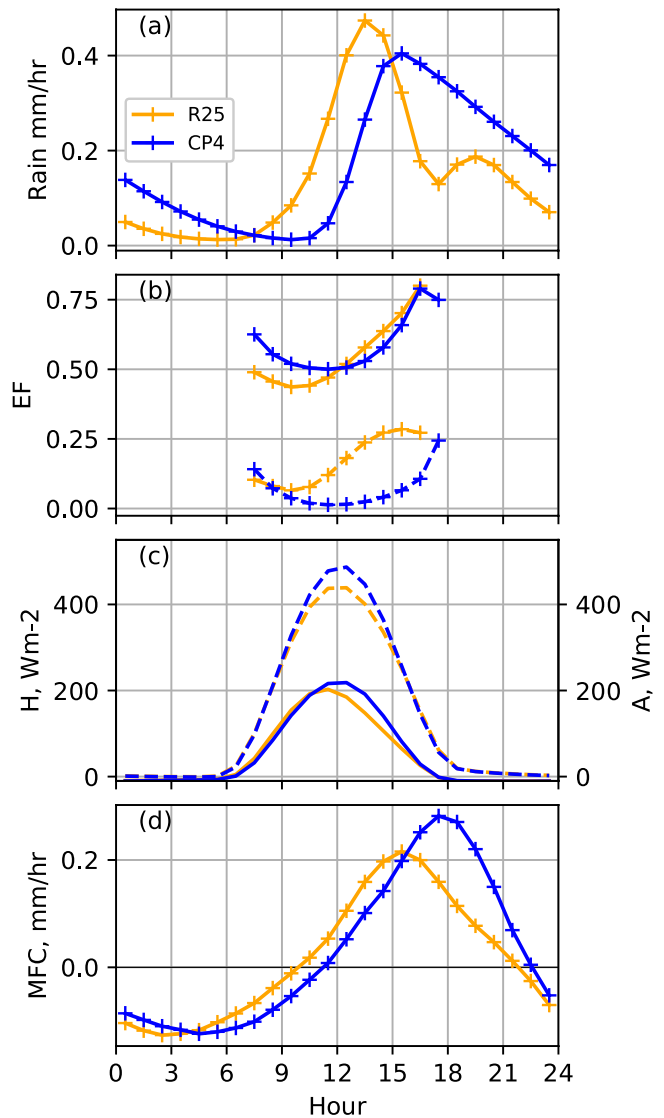

Fig. 5 Diurnal cycles over land ( -8 to $6^{\circ} \mathrm{E}, 5-10^{\circ} \mathrm{N}$ ) averaged over March, April and May for a rainfall, $\mathbf{b}$ day time evaporative fraction (solid) and its contribution from canopy evaporation (dashed) $\mathbf{c}$ sensible heat (solid) and available energy (dashed) and $\mathbf{d}$ total column moisture flux convergence

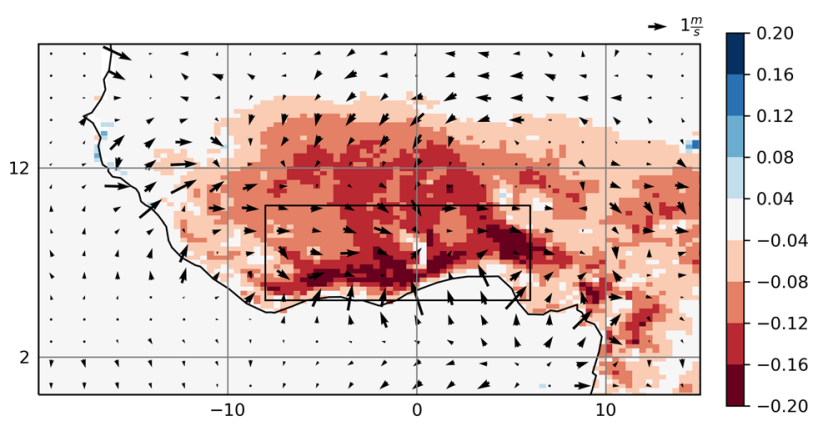

Fig. 6 As for Fig. 4c but showing West Africa, vectors indicate the difference (CP4-R25) in modelled mean daytime (0500-1700 LT) $10 \mathrm{~m}$ winds

(between 1 and $3 \mathrm{~m}$ depth). Figure $7 \mathrm{~m}, \mathrm{n}$, o show the month on month change in soil moisture storage summed across all four model soil levels. This shows the extent to which soil water is replenished by rainfall (throughfall) and its reduction in the dry season by drainage, transpiration and bare soil evaporation. The seasonal soil moisture amplitude in the whole soil column is $50 \%$ higher for CP4, $259 \mathrm{~mm}$ in the equatorial latitudes, compared to $184 \mathrm{~mm}$ in R25. Total evaporation (the sum of evaporation from bare soil, transpiration and canopy evaporation (Fig. 7p, q, r) is markedly lower in CP4 within the climatological rain band. This again highlights the key role of rapid re-evaporation of water intercepted by the canopy in explaining the different land-atmosphere coupling in the two simulations. Only as the rain band retreats southwards in September to December is there evidence of enhanced total evaporation in CP4 over Tropical North Africa (Fig. 7r). This brief post-rainy season effect in CP4 is due principally to an extended period of transpiration, which can be maintained because of increased root zone soil moisture. Overall, the slower evaporative response of $\mathrm{CP} 4$ favours a stronger influence of soil moisture (rather than canopy water) on surface fluxes. Finally, Fig. $7 \mathrm{~s}$, t, u reveals a strong inter-model difference in P-E, which at monthly time scales is equivalent to atmospheric moisture flux convergence, because change in atmospheric moisture storage om this time scale is close to zero. In the most active phases of the climatological rain band, P-E in CP4 is dramatically different, reaching values of up to $60 \mathrm{~mm} / \mathrm{month}$, or up to 2 times higher than R25. For the atmospheric water balance, enhanced moisture convergence into the rainband in $\mathrm{CP} 4$ helps to offset the loss of rapidly recycled moisture from the surface.

In this pair of simulations, it is more challenging to identify the impact on the atmosphere of root zone soil moisture than canopy water. That is because in R25, the coupling between canopy water and total evaporation is so strong that any analysis of the two models during rainy months will be dominated by interception. Instead we examine the impact of post-rainy season soil moisture anomalies on atmospheric circulation. Such feedbacks are also likely to be operating within the rainy season, and potentially affecting rainfall, though in the case of R25, we would expect the soil moisture pathway to be bypassed by canopy interception. As discussed above, there are strong contrasts in surface fluxes between R25 and CP4 in Tropical North Africa during the onset of the dry season in October and November. We consider the response in November across West Africa when rainfall and interception are negligible and the role of soil moisture is most clearly expressed. Focusing on West Africa, Fig. 8 shows that daytime (0500 to $1700 \mathrm{LT})$ sensible heat fluxes are typically $20-60 \mathrm{Wm}^{-2}$ lower in CP4 than R25, equivalent to a decrease of $30-50 \%$. This is driven by enhanced root zone soil moisture in $\mathrm{CP} 4$ from increased infiltration in the preceding months. Covering an area $2500 \times 1000 \mathrm{~km}$, the negative surface heating anomaly is strong enough to induce a divergent anomaly in the regional scale circulation. This feedback suppresses moisture flux convergence into the region, and would effectively act as a negative soil 
moisture-precipitation feedback if synoptic conditions were favourable for storms.

\section{Discussion}

The recent application of CPMs for climate studies raises important questions about the fate of rainfall once it reaches the ground, and its potential feedback on the atmosphere. The higher rain rates produced by CPMs would be expected to substantially increase surface runoff in comparison to conventional models with parameterised convection via higher infiltration excess runoff. We do see that effect in our analysis, though the increase in total surface runoff when comparing CP4 with R25 (amounting to 8\% of total rainfall) is modest compared to the change in high intensity rainfall (with a $25 \%$ increase in rainfall above $20 \mathrm{~mm} \mathrm{~h}^{-1}$ ). The effect of enhanced surface runoff in CP4 is limited for two reasons. Firstly, the sub-grid rainfall distribution assumed by the land surface scheme in R25 allows significant runoff to be generated even at rainfall rates of $10 \mathrm{~mm} \mathrm{~h}^{-1}$. Secondly, both simulations have high values of saturated hydraulic conductivity (from the uniformly sandy soils) and this limits infiltration-excess runoff overall. On the other hand, for the sandy soils adopted in these simulations, there is relatively rapid moisture transport down the profile and into sub-surface runoff. Indeed the increase for CP4 (compared to R25) in sub-surface runoff is of a similar magnitude to the increase due to surface runoff. Taken together, total runoff in $\mathrm{CP} 4$ appears very high compared to available observational estimates (Table 1).

Relatively speaking, there is a much larger difference in interception loss than surface runoff between models. In this case, the sub-grid rainfall distribution cannot offset the impact of strong biases in rainfall forcing in R25 (i.e. overly frequent light rain). As a result, interception loss is unrealistically high in R25. The additional throughfall simulated by CP4 helps to offset soil moisture losses due to runoff, and allows $\mathrm{CP} 4$ to maintain higher rates of transpiration, which extend further into the dry season. Importantly, the effect of reduced wet season evapotranspiration in CP4 does not simply translate to increased sensible heat flux, as CP4 also receives less insolation due to differences in the cloud scheme (Stratton et al. 2018). This is in contrast to the situation described by (Ban et al. 2014) over Europe, where drier soils in a CPM combined with increased insolation to amplify warm biases found in a coarser resolution version of the model.

Although R25 is capable of producing high intensity rainfall on the model time-step (Martin et al. 2017), our study shows that the frequency of low intensity rainfall $\left(<1 \mathrm{~mm} \mathrm{day}^{-1}\right)$ remains a dominant control on the overall surface hydrological response. We see a strong impact of interception errors in R25 on the diurnal cycle. The switch to a latent-dominated energy balance in the afternoon means that the model effectively brings forward the phase of maximum surface heating by $1-2 \mathrm{~h}$. This reduces moisture flux convergence in the afternoon, limiting the ability of that model to sustain rainfall into the evening. Similar impacts of surface heating on the diurnal moisture flux over West Africa have been discussed previously by Birch et al. (2014), though there the differences were in association with cloud cover, affecting total available energy, rather than its partition. On the other hand, an impact of differences in interception loss on land-sea pressure differences and convergence has been identified in sub-seasonal simulations over India with an earlier version of this model (Willetts et al. 2017). The change in rainfall frequency and diurnal timing which is often reported when switching off parameterisations of deep convection is expected to affect the surface radiation budget through changes in cloud cover. We found differences in surface insolation here, though it was not possible to isolate the impact of the representation of convection from the effect of using different cloud schemes in the two simulations. Along with the potential for land feedbacks via hydrological pathways that was our focus, CP modellers should also consider radiative land feedbacks, particularly in regions (and models) where evapotranspiration is less sensitive to the frequency and intensity of rainfall.

This study suggests that the assumptions made in the exponential distribution of sub-grid rainfall need to be revisited for both convection-permitting and parameterised configurations of this model. The inability of the sub-grid scheme to overcome the overly frequent light rain in R25 (and presumably also other coarse resolution configurations of the model) suggests a need for further model development. We note that as well as the description of convection, differences in horizontal resolution between the two simulations could also impact the simulated hydrological pathways. Given the fundamental differences in both the rainfall characteristics and the representation of sub-grid hydrology however, we expect resolution effects to be minor. Moreover, our comparisons of the surface and atmospheric water budgets (for example in Fig. 7) are performed over large regions rather than at the grid point scale. The excessive amount of time during the day when the vegetation canopy is wet also has implications for other aspects of the model not explored here. For example, the transpiration pathway is effectively bypassed whenever the canopy is wet. A canopy that remains wetted through overly frequent rainfall can also reduce the sensitivity of interception loss to canopy capacity differences from different land covers. Together these factors may impact simulations of deforestation, and deleteriously impact on plant productivity, which would compromise the carbon cycle simulated in future Earth System type configurations of the model. Our results also raise the question of 

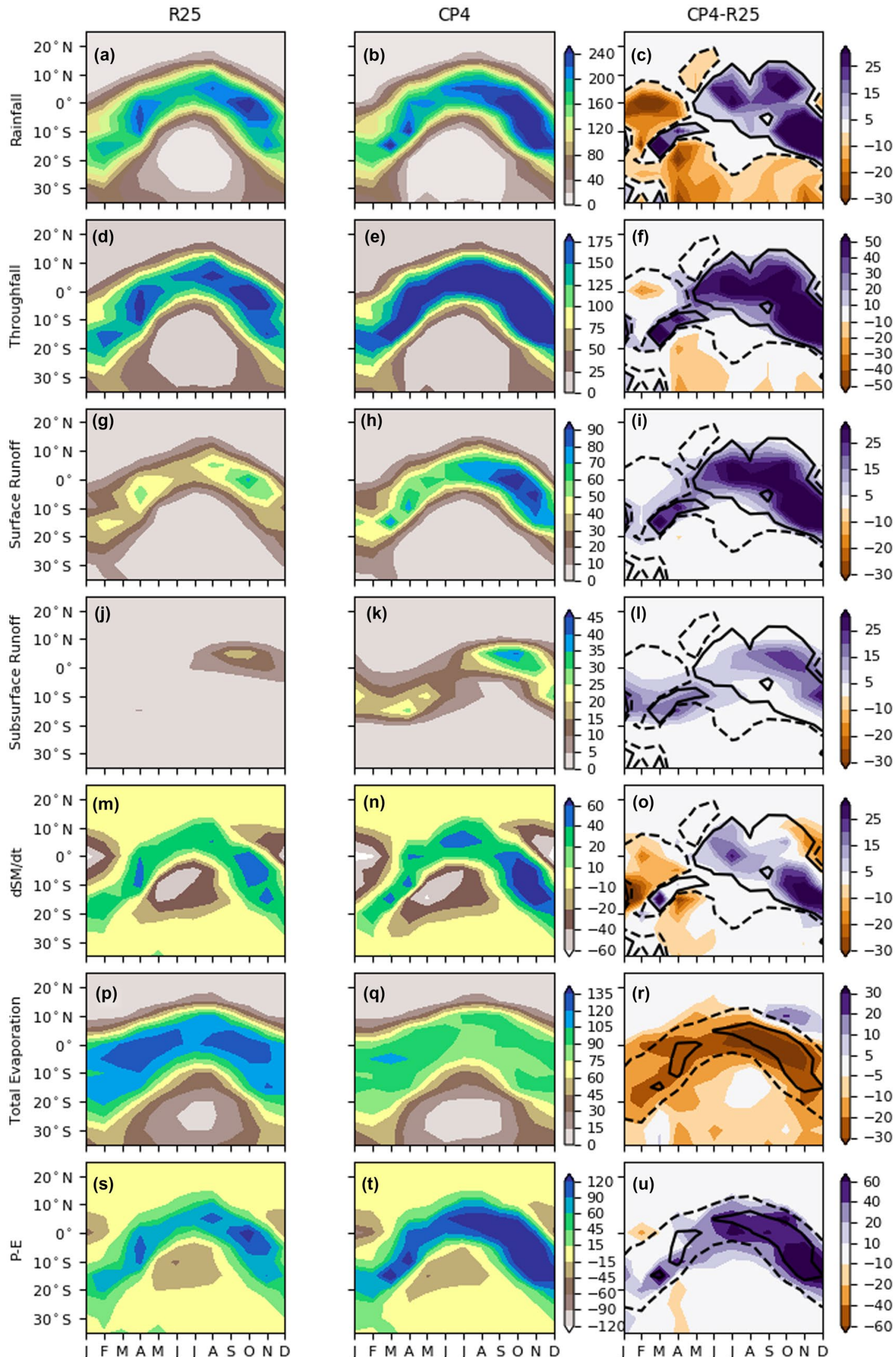
४Fig. 7 Zonal mean of modelled water balance components for R25 (left column), CP4 (middle) and model difference (CP4-R25; right). With each component shown in rows: rainfall (P; top row), throughfall (row 2), surface runoff (row 3), sub surface runoff (row 4), change in total column soil moisture (dSM/dt; row 5), total evaporation from the surface (row 6) and P-E (bottom), all units in $\mathrm{mm} / \mathrm{month}$. The contours on the difference plots $(\mathbf{c}, \mathbf{f}, \mathbf{i}, \mathbf{l}, \mathbf{o})$ indicate model rainfall differences (CP4 minus R25) of $\pm 5 \mathrm{~mm}$. The contours on the difference plots $(\mathbf{r}, \mathbf{u})$ indicate mean modelled rainfall in CP4 of 100 and $200 \mathrm{~mm} / \mathrm{month}$

whether there is still a need for a sub-grid rainfall assumption in a CPM given that, unlike in GCMs, grid box rainfall rates are already large enough to trigger infiltration-excess runoff.

\section{Conclusion}

The pioneering 10 year convection permitting simulation over Africa has provided the opportunity to examine the role of the land surface under a wholly different rainfall regime to that in which these models have been developed. Convection-permitting models offer significant improvement on the depiction of rainfall intensities. Our results show this has a significant impact on the surface hydrology, and in turn on how that can feed back on the atmosphere.

We find that averaged across the continent, the CP4 model produces very similar annual rainfall to R25, and to observed values, but with large contrasts in the partitioning of that rain into the different hydrological pathways. Annual ET falls sharply in CP4, amounting to a decrease of $13 \%$ of total rain, and taking it below the range of estimates in the literature. The drop in ET is almost entirely due to a reduction in the re-evaporation of rainfall intercepted by the canopy, which in R25 appears unrealistically high when considering observational evidence. With ET suppressed, there is a much greater contribution to rainfall in the atmospheric water budget from moisture flux convergence. This is particularly clear within the rain band that migrates seasonally across the continent.

The drop in ET is almost entirely due to a reduction in the re-evaporation of rainfall intercepted by the canopy, which in R25 appears unrealistically high. Excessive canopy interception in R25 is due to overly-frequent light rain typical of coarse resolution models. Even with a sub-grid rainfall distribution assumed, the surface scheme is unable to adequately address this bias. As a result of excessive canopy interception in $\mathrm{R} 25$, in combination with a typical rainfall diurnal cycle bias, sensible heat in R25 weakens rapidly in the afternoon, an effect which feeds back on sea breeze circulations and moisture flux convergence.

Relative to R25, throughfall is increased in the CP4 simulation, and occurs less frequently but at higher rates. This shift in intensity distribution triggers an increase in surface runoff in CP4 equivalent to $9 \%$ of total rain. More rain also infiltrates into the soil in CP4, producing a larger amplitude seasonal cycle of soil moisture and increased sub-surface runoff. Evidence indicates that where increased soil moisture storage allows enhanced transpiration during the dry season, the impact of accompanying suppressed sensible heat in CP4 can induce a regional scale divergent flow.

This study shows how, even when total continental rain remains unchanged, switching a convective parameterisation off can substantially impact land surface behaviour, via changes in timing and intensity of rainfall, which in turn can feedback on the atmosphere. With the increasing use of CPMs for climate simulations, we suggest that detailed diagnosis is needed of how existing land parameterisations, usually developed for GCM studies, respond to the more realistic rainfall forcing that CPMs produce. 
Fig. 8 Model differences (CP4 minus R25) in November mean daytime (0500-1700 LT) sensible heat, vectors show the difference in daytime (0500-1700 LT) $10 \mathrm{~m}$ winds

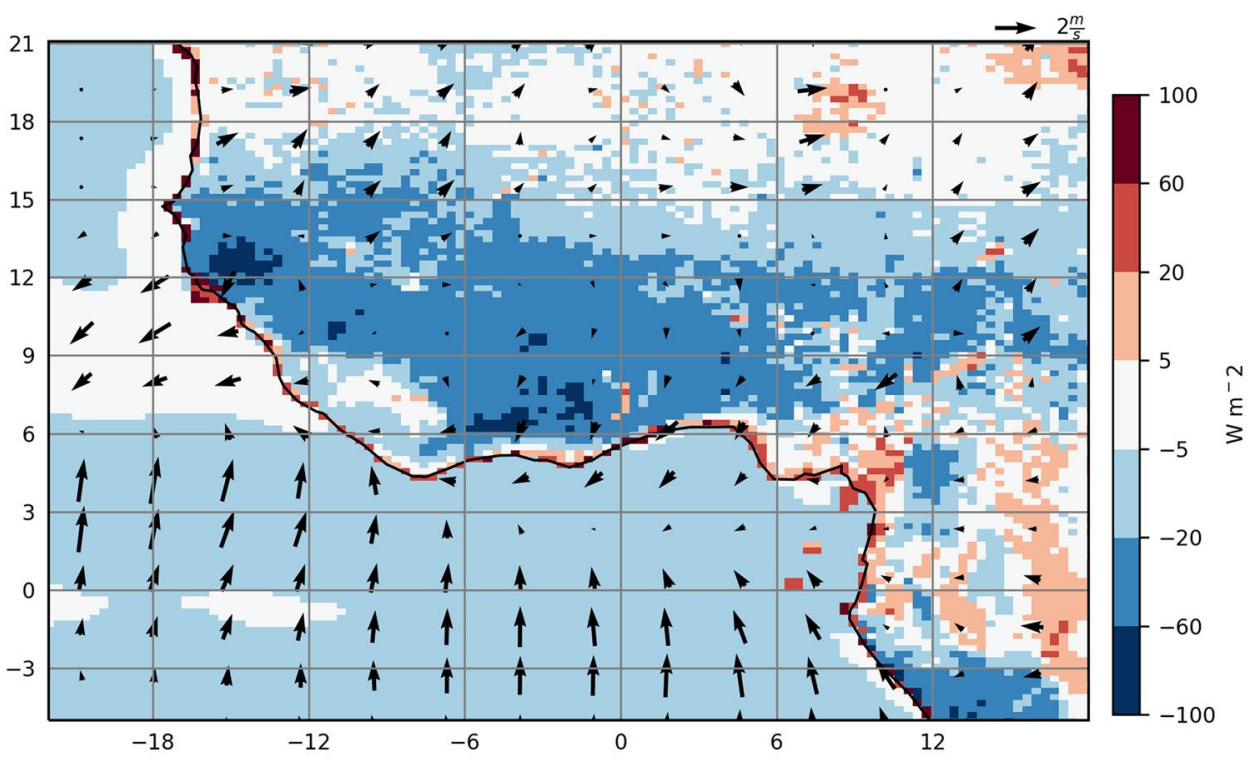

Acknowledgements The authors were supported by the Natural Environment Research Council/Department for International Development via the Future Climate for Africa (FCFA) funded project Improving Model Processes for African Climate (IMPALA; NE/M017214/1 and NE/M017230/1). The authors wish to thank the three anonymous reviewers for their comments and suggestions.

Funding The authors were supported by the Natural Environment Research Council/Department for International Development via the Future Climate for Africa (FCFA) funded project Improving Model Processes for African Climate (IMPALA; NE/M017214/1 and NE/ M017230/1).

Availability of data and material The UM model datasets analysed during the current study are available on the CEDA Archive, https:// catalogue.ceda.ac.uk/uuid/a6114f2319b34a58964dfa5305652fc6\#colla pseOne.

Code availability Not Applicable.

\section{Declarations}

\section{Conflict of interest Not Applicable.}

Open Access This article is licensed under a Creative Commons Attribution 4.0 International License, which permits use, sharing, adaptation, distribution and reproduction in any medium or format, as long as you give appropriate credit to the original author(s) and the source, provide a link to the Creative Commons licence, and indicate if changes were made. The images or other third party material in this article are included in the article's Creative Commons licence, unless indicated otherwise in a credit line to the material. If material is not included in the article's Creative Commons licence and your intended use is not permitted by statutory regulation or exceeds the permitted use, you will need to obtain permission directly from the copyright holder. To view a copy of this licence, visit http://creativecommons.org/licenses/by/4.0/.

\section{References}

Ban N, Schmidli J, Schar C (2014) Evaluation of the convection-resolving regional climate modeling approach in decade-long simulations. J Geophys Res-Atmos. https://doi.org/10.1002/2014JD0214 78

Ban N et al (2021) The first multi-model ensemble of regional climate simulations at kilometer-scale resolution, part I: evaluation of precipitation. Clim Dyn 57:275-302

Berthou S, Rowell DP, Kendon EJ, Roberts MJ, Stratton RA, Crook JA, Wilcox C (2019) Improved climatological precipitation characteristics over West Africa at convection-permitting scales. Clim Dyn 53:1991-2011

Best MJ et al (2011) The Joint UK land environment simulator (JULES), model description part 1: energy and water fluxes. Geosci Model Dev 4:677-699

Beven K, Kirkby M (1979) A physically based, variable contributing area model of basin hydrology. Hydrol Sci Bull 24:26

Birch CE, Parker DJ, Marsham JH, Copsey D, Garcia-Carreras L (2014) A seamless assessment of the role of convection in the water cycle of the west African monsoon. J Geophys Res-Atmos 119:2890-2912. https://doi.org/10.1002/2013JD020887

Clark P, Roberts N, Lean H, Ballard SP, Charlton-Perez C (2016) Convection-permitting models: a step-change in rainfall forecasting. Meteorol Appl 23:165-181. https://doi.org/10.1002/met.1538

Crook J, Klein C, Folwell S, Taylor CM, Parker DJ, Stratton R, Stein $\mathrm{T}$ (2019) Assessment of the representation of west african storm lifecycles in convection-permitting simulations. Earth Space Sci 6:818-835

Cuartas LA, Tomasella J, Nobre AD, Hodnett MG, Waterloo MJ, Munera JC (2007) Interception water-partitioning dynamics for a pristine rainforest in Central Amazonia: marked differences between normal and dry years. Agric for Meteorol 145:69-83. https://doi.org/10.1016/j.agrformet.2007.04.008

Czikowsky MJ, Fitzjarrald DR (2009) Detecting rainfall interception in an Amazonian rain forest with eddy flux measurements. J Hydrol 377:92-105. https://doi.org/10.1016/j.jhydrol.2009.08.002

Dai A (2006) Precipitation characteristics in eighteen coupled climate models. J Clim 19:4605-4630

Dai A, Trenberth KE (2002) Estimates of freshwater discharge from continents: latitudinal and seasonal variations. J Hydrometeorol 
3:660-687. https://doi.org/10.1175/1525-7541(2002)003\% 3c0660:Eofdfc\%3e2.0.Co;2

Davies-Barnard T, Valdes PJ, Jones CD, Singarayer JS (2014) Sensitivity of a coupled climate model to canopy interception capacity. Clim Dyn 42:1715-1732

Decharme B, Douville H (2007) Global validation of the ISBA subgrid hydrology. Clim Dyn 29:21-37

Demott CA, Randall DA, Khairoutdinov M (2007) Convective precipitation variability as a tool for general circulation model analysis. $\mathrm{J}$ Clim 20:91-112. https://doi.org/10.1175/JCLI3991.1

Dolman AJ, Gregory D (1992) The parametrization of rainfall interception in Gcms. Q J R Meteorol Soc 118:455-467

Fiedler S et al (2020) Simulated tropical precipitation assessed across three major phases of the coupled model intercomparison project (CMIP). Mon Weather Rev 148:3653-3680

Finney DL et al (2019) Implications of improved representation of convection for the East Africa water budget using a convectionpermitting model. J Clim 32:2109-2129

Funk C et al (2015) The climate hazards infrared precipitation with stations-a new environmental record for monitoring extremes. Sci Data. https://doi.org/10.1038/sdata.2015.66

Guichard F et al (2004) Modelling the diurnal cycle of deep precipitating convection over land with cloud-resolving models and singlecolumn models. Q J R Meteorol Soc 130:3139-3172

Hart NCG, Washington R, Stratton RA (2018) Stronger local overturning in convective-permitting regional climate model improves simulation of the subtropical annual cycle. Geophys Res Lett 45:11334-11342. https://doi.org/10.1029/2018GL079563

Hohenegger C, Brockhaus P, Bretherton CS, Schar C (2009) The soil moisture-precipitation feedback in simulations with explicit and parameterized convection. J Clim 22:5003-5020

Hu HC, Leung LR, Feng Z (2020) Observed warm-season characteristics of MCS and Non-MCS rainfall and their recent changes in the central United States. Geophys Res Lett. https://doi.org/10. 1029/2019GL086783

Hutjes RWA, Wierda A, Veen AWL (1990) Rainfall interception in the Tai Forest, Ivory-Coast application of 2 simulation-models to a humid tropical system. J Hydrol 114:259-275

Jackson LS et al (2020) The effect of explicit convection on couplings between rainfall humidity, and ascent over Africa under climate change. J Clim 33:8315-8337. https://doi.org/10.1175/ Jcli-D-19-0322.1

Jung M et al. (2019) The FLUXCOM ensemble of global land-atmosphere energy fluxes Sci Data 6

Kendon EJ, Roberts NM, Senior CA, Roberts MJ (2012) Realism of rainfall in a very high-resolution regional climate model. J Clim 25:5791-5806

Klingaman NP, Martin GM, Moise A (2017) ASoP (v1.0): a set of methods for analyzing scales of precipitation in general circulation models. Geosci Model Dev 10:57-83

Lawrence DM, Thornton PE, Oleson KW, Bonan GB (2007) The partitioning of evapotranspiration into transpiration, soil evaporation, and canopy evaporation in a GCM: Impacts on land-atmosphere interaction. J Hydrometeorol 8:862-880. https://doi.org/10.1175/ JHM596.1

Lean HW, Clark PA, Dixon M, Roberts NM, Fitch A, Forbes R, Halliwell C (2008) Characteristics of high-resolution versions of the Met Office Unified Model for forecasting convection over the United Kingdom. Mon Weather Rev 136:3408-3424

Li PX, Furtado K, Zhou TJ, Chen HM, Li J, Guo Z, Xiao C (2020) The diurnal cycle of East Asian summer monsoon precipitation simulated by the Met Office Unified Model at convection-permitting scales. Clim Dyn 55:131-151

Lian X et al (2018) Partitioning global land evapotranspiration using CMIP5 models constrained by observations. Nat Clim Change $8: 640$
Lloyd CR, Gash JHC, Shuttleworth WJ, Marques AD (1988) The measurement and modeling of rainfall interception by Amazonian rainforest. Agric for Meteorol 43:277-294

Martens B et al (2017) GLEAM v3: satellite-based land evaporation and root-zone soil moisture. Geosci Model Dev 10:1903-1925

Martin GM, Klingaman NP, Moise AF (2017) Connecting spatial and temporal scales of tropical precipitation in observations and the MetUM-GA6. Geosci Model Dev 10:105-126. https://doi.org/10. 5194/gmd-10-105-2017

Miralles DG, De Jeu RAM, Gash JH, Holmes TRH, Dolman AJ (2011) Magnitude and variability of land evaporation and its components at the global scale. Hydrol Earth Syst Sc 15:967-981

Moore RJ (1985) The probability-distributed principle and runoff production at point and basin scales. Hydrolog Sci J 30:273-297

Pichelli E et al (2021) The first multi-model ensemble of regional climate simulations at kilometer-scale resolution part 2: historical and future simulations of precipitation. Clim Dyn 56:3581-3602

Poulter B et al (2015) Plant functional type classification for earth system models: results from the European Space Agency's land cover climate change initiative. Geosci Model Dev 8:2315-2328

Prein AF et al (2015) A review on regional convection-permitting climate modeling: demonstrations, prospects, and challenges. Rev Geophys 53:323-361

Rodell M, Beaudoing HK, L'Ecuyer TS, Olson WS, Famiglietti JS, Houser PR, Adler R, Bosilovich MG, Clayson CA, Chambers D, Clark E, Fetzer EJ, Gao X, Gu G, Hilburn K, Huffman GJ, Lettenmaier DP, Liu WT, Robertson FR, Schlosser CA, Sheffield J, Wood EF (2015) The observed state of the water cycle in the early twenty-first century. J Clim 28(21):8289-8318. https://doi. org/10.1175/JCLI-D-14-00555.1

Schmidt GA et al (2006) Present-day atmospheric simulations using GISS ModelE: comparison to in situ, satellite, and reanalysis data. J Clim 19:153-192

Scott R, Koster RD, Entekhabi D, Suarez MJ (1995) Effect of a canopy interception reservoir on hydrological persistence in a generalcirculation model. J Clim 8:1917-1922

Senior C et al (2021) Convection permitting regional climate change simulations for understanding future climate and informing decision making in Africa. Bull Am Meteorol Soc. https://doi.org/10. 1175/BAMS-D-20-0020.1

Shuttleworth WJ (1988) Evaporation from Amazonian rainforest. Proc R Soc Ser B 233:321-346

Smith RNB (1990) A scheme for predicting layer clouds and their water-content in a general-circulation model. Q J R Meteorol Soc 116:435-460

Stephens GL et al (2010) Dreary state of precipitation in global models. J Geophys Res-Atmos. https://doi.org/10.1029/2010JD014532

Stevens B et al (2019) DYAMOND: the dynamics of the atmospheric general circulation modeled on non-hydrostatic domains. Prog Earth Planet Sci. https://doi.org/10.1186/s40645-019-0304-z

Stratton RA et al (2018) A pan-African convection-permitting regional climate simulation with the met office unified model: CP4-Africa. J Clim 31:3485-3508. https://doi.org/10.1175/Jcli-D-17-0503.1

Sun J, Pritchard MS (2016) Effects of explicit convection on global land-atmosphere coupling in the superparameterized. CAM J Adv Model Earth Syst 8:1248-1269

Taylor CM, Birch CE, Parker DJ, Dixon N, Guichard F, Nikulin G, Lister GMS (2013) Modeling soil moisture-precipitation feedback in the Sahel: Importance of spatial scale versus convective parameterization. Geophys Res Lett 40:6213-6218

Tobon Marin C, Bouten W, Sevink J (2000) Gross rainfall and its partitioning into throughfall, stemflow and evaporation of intercepted water in four forest ecosystems in western. Amazon J Hydrol 237:40-57. https://doi.org/10.1016/S0022-1694(00)00301-2

Urabana VN (1997) Observations and modelling of rainfall interception at two experimental sites in Amazonia. In: Gash JHC, Nobre 
CA, Roberts JM, Victoria RL, Baldocchi D (eds) Amazonian deforestation and climate. John Wiley, Chichester, pp 151-162

van Genuchten M (1980) A closed-form equation for predicting the hydraulic conductivity of unsaturated soils. Soil Sci Soc Am J 44:6. https://doi.org/10.2136/sssaj1980.03615995004400050002x

Walters D et al (2019) The met office unified model global atmosphere 7.0/7,1 and JULES global land 7.0 configurations. Geosci Model Dev 12:1909-1963

Wang DG, Wang GL, Anagnostou EN (2009) Impact of sub-grid variability of precipitation and canopy water storage on hydrological processes in a coupled land-atmosphere model. Clim Dyn 32:649-662

Weedon GP et al (2011) Creation of the WATCH forcing data and its use to assess global and regional reference crop evaporation over land during the twentieth century. J Hydrometeorol 12:823-848. https://doi.org/10.1175/2011JHM1369.1
Willetts PD, Marsham JH, Birch CE, Parker DJ, Webster S, Petch J (2017) Moist convection and its upscale effects in simulations of the Indian monsoon with explicit and parametrized convection. Q J R Meteorol Soc 143:1073-1085

Wilson DR, Bushell AC, Kerr-Munslow AM, Price JD, Morcrette CJ (2008) PC2: a prognostic cloud fraction and condensation scheme. I: Scheme description. Q J R Meteorol Soc 134:2093-2107

Wiltshire AJ et al (2020) JULES-GL7: the Global Land configuration of the Joint UK Land Environment Simulator version 7.0 and 7.2. Geosci Model Dev 13:483-505

Wood EF, Lettenmaier DP, Zartarian VG (1992) A land-surface hydrology parameterization with subgrid variability for general-circulation models. J Geophys Res-Atmos 97:2717-2728

Publisher's Note Springer Nature remains neutral with regard to jurisdictional claims in published maps and institutional affiliations. 